\title{
REPRESENTATIVIDADE E POTENCIAL DE UTILIZAÇÃO DE UM BANCO DE DADOS DE SOLOS DO BRASIL ${ }^{(1)}$
}

\author{
Marcelo Muniz Benedetti(2), Gerd Sparovek ${ }^{(3)}$, Miguel Cooper $^{(4)}$, \\ Nilton Curi ${ }^{(5)}$ \& Amaury de Carvalho Filho ${ }^{(6)}$
}

\begin{abstract}
RESUMO
O Brasil ocupa uma posição de destaque em estudos de solos tropicais, em razão do enorme volume de informações levantadas sobre os solos do país. Entretanto, a disponibilização dessas informações tem-se mostrado pouco eficiente. Com o intuito de ampliar as possibilidades de utilização de uma base de dados de solos de abrangência nacional, elaborada a partir de levantamentos pedológicos de grande amplitude, procedeu-se à sua reestruturação, atualizando a classificação dos perfis de solo que a constituem, seguida de uma avaliação quanto à sua representatividade e potencial para análises qualitativas. Para isso, os dados foram organizados em formato de banco de dados e a classificação pedológica atualizada de acordo com a versão mais recente do Sistema Brasileiro de Classificação de Solos, até o quarto nível categórico. Essa atualização foi, em geral, bastante satisfatória, sobretudo nos três primeiros níveis hierárquicos, com maiores restrições no subgrupo, conforme a análise dos graus de confiabilidade adotados para expressar a exatidão no ajuste do enquadramento taxonômico. Desse modo, ao suprir a carência de uma nomenclatura unificada e ajustada aos critérios atuais que regem a classificação de solos no Brasil, constituiu-se um banco de dados comparável qualitativamente com variáveis externas, como distribuição geográfica, altitude e tipos climáticos. As avaliações realizadas a partir dessa base evidenciaram uma boa representatividade da distribuição dos perfis na grande maioria dos estados da federação, assim como em relação às condições ambientais representadas por zonas e tipos climáticos da classificação de Köppen. Entretanto, não foram constatadas correlações estreitas entre estas variáveis e as classes de solo em nível de ordem, embora algumas tendências gerais tenham sido observadas, como uma significativa proporção de perfis de Vertissolos e Luvissolos sob clima
\end{abstract}

\footnotetext{
(1) Parte de Dissertação de Mestrado apresentada a Escola Superior de Agricultura "Luiz de Queiroz" ESALQ/USP. Recebido para publicação em agosto de 2006 e aprovado em outubro de 2008.

(2) Engenheiro-Agrônomo, Mestrando do Departamento de Ciência do Solos, Escola Superior de Agricultura "Luiz de Queiroz" ESALQ. Caixa Postal 09, Av. Pádua Dias 11, CEP 13418-900 Piracicaba (SP). E-mail: mbenedetti@ctc.com.br

${ }^{(3)}$ Professor do Departamento de Ciência do Solo, ESALQ/USP. E-mail: gerd@.usp.br

(4) Professor do Departamento de Ciência do Solo, ESALQ/USP. E-mail: mcooper@esalq.usp.br

(5) Professor do Departamento de Ciência do Solo, Universidade Federal de Lavras - DCS/UFLA. Caixa Postal 37, CEP 37200-000 Lavras (MG).E-mail: niltcuri@ufla.br

(6) Pesquisador da Embrapa Solos, Doutorando do Departamento de Solos e Nutrição de Plantas, Universidade Federal de Lavras. MG CEP 37200-000. E-mail: amaury@cnps.embrapa.br
} 
semi-árido (BS). De forma semelhante, a altitude de onde ocorrem as classes de solos foi também muito variável, mas os valores de quartis e mediana indicaram algumas faixas preferenciais. Assim, Cambissolos e Latossolos tendem a ocupar os níveis mais altos da paisagem brasileira, ao passo que $75 \%$ dos perfis de Espodossolos e de Plintossolos situam-se em cotas inferiores a $200 \mathrm{~m}$. Além das potencialidades de uso evidenciadas, a estruturação atual da base de dados permite outras aplicações para atender necessidades específicas de estudo, inclusive no que tange a investigações relacionadas ao sistema de classificação de solos que vem sendo desenvolvido no país.

Termos de indexação: Sistema brasileiro de classificação de solos, modelo digital do terreno, classificação climática de Köppen, geoprocessamento.

\title{
SUMMARY: COVERAGE AND POTENTIAL USE OF A SOIL PROFILE DATABASE IN BRAZIL
}

\begin{abstract}
Brazilian soil science is outstanding in tropical soil research, with a wealth of information on the soils of the country. However, this knowledge is not readily available. The aim of this study was to increase the range of a national soil profile database, based on soil surveys of wide extent. The soil taxonomy was updated based on the latest version of the Brazilian Soil Classification System. The updated database was also evaluated for coverage and potential for quantitative analyses. For this purpose, the data were arranged in an electronic database and soil classification updated up to the fourth categorical level of the current taxonomic system. Mainly in the first three levels, the name updating procedure was reliable. Restrictions were observed at the fourth level (sub-group), as measured by the degree of confidence used for the assessment of taxonomic classification accuracy. By updating the soil profiles to the current and standard taxonomic criteria, the databases were internally standardized and became comparable to external data, e.g. spatial distribution, altitude and climate types. Profiles of the different taxonomic groups nationwide were well- represented, as well as most federal States. Furthermore, soil profiles from several taxonomic groups were related to the Köppen climate zones and types. A relation between the first soil taxonomic level (soil type) and climate was not always evident, with some exceptions e.g. a substantial portion of Vertisols and Luvisols occur in semi-arid climate (BS). The altitude of soil type occurrence was also variable, with some indications of quartile and median preferences for some soils. Cambisols and Latosols were more frequent at higher altitudes, whereas $75 \%$ of the Espodosols and Plintosols are found at below 200 masl. The analysis of the database proposed here can be further complemented for specific study needs, including adaptations to ongoing modifications of the taxonomy of the Brazilian Soil Classification System.
\end{abstract}

Index terms: Brazilian Soil Classification System, DEM, Köppen climate classification, GIS.

\section{INTRODUÇÃO}

O conhecimento dos recursos naturais (solos, clima, vegetação e relevo) constitui parte do embasamento indispensável para a avaliação do potencial de uso das terras. Estas informações, combinadas com os contextos sociais, econômicos e culturais, levam à possibilidade de análise das oportunidades, das restrições e dos impactos ligados ao uso da terra. Desse modo, é possível identificar áreas com maior ou menor aptidão para as mais diversas atividades, sejam agrícolas ou não, considerando aspectos de eqüidade e justiça social e responsabilidade no uso dos recursos naturais, visando benefícios coletivos. Para analisar fenômenos dessa amplitude, relacionados com as ciências que estudam o uso da terra, é preciso que se crie um banco de dados consistente, georreferenciado e quantitativo (Cooper et al., 2005).

A maneira como são armazenadas em um banco de dados facilita a organização, a consulta e a atualização das informações. Com isso, os mesmos dados podem ser utilizados para aplicações diferentes, reduzindo espaço e esforço (Assad \& Sano, 1998). Como exemplos de bancos de dados referentes a solo podem ser citados: (a) o Mapa Digital de Solos do Mundo (FAO, 1996), (b) o SOTER - The World Soils and Terrain Database (van Engelen, 1999), (c) o CANSIS Canadian Soil Information System (Coote \& McDonald, 1999), (d) o NASIS - National Soil Information System (Soil Survey Staff, 1991), (e) o Hydraulic Properties of European Soils (HYPRES) 
database (Nemes et al., 1999), e (f) o Unsatured Soil Hydraulic Database (UNSODA), já em sua segunda versão (Nemes et al., 2001).

O Brasil ocupa uma posição de destaque em estudos de solos tropicais, tendo gerado enorme volume de informações pedológicas por meio de levantamentos de solos de grande abrangência, com registros tanto de caráter geral quanto referentes a condições locais. No entanto, a disponibilização destas informações temse mostrado pouco eficiente em razão do grande volume, da complexidade e da pouca normatização dos dados, o que tem dificultado e limitado sua utilização. A ampliação do acesso a essa informação é, portanto, imprescindível para seu melhor aproveitamento.

Neste sentido, a partir de levantamentos de solo realizados pelo antigo Serviço Nacional de Levantamento e Conservação de Solos (SNLCS) da Embrapa (atual Embrapa Solos) e órgãos antecessores, e pelo Projeto RADAM Brasil, foi desenvolvida uma base de dados de solos brasileiros (Cooper et al., 2005). Esta base, por falta de uma classificação unificada e atualizada dos perfis de solo, devido a mudanças em nomenclatura e critérios de distinção taxonômica no decorrer do tempo, permitia apenas avaliações de caráter quantitativo.

No contexto descrito, este trabalho propõe uma análise da estrutura dessa base de dados de solos brasileiros (Cooper et al., 2005), de forma a disponibilizar uma estrutura mais prática, e avaliar as possibilidades de sua aplicação em análises qualitativas de variáveis externas.

\section{MATERIAL E MÉTODOS}

Este trabalho utilizou informações oriundas de levantamentos de solo de escala regional que cobrem grande parte do território brasileiro, integrantes de uma base de dados de acesso comunitário, implementada a partir da introdução, em planilhas do Microsoft Excel ${ }^{\circledR}$, de um conjunto de características relativas a perfis de solo e resultados analíticos de um horizonte superficial e outro subsuperficial de cada perfil (Cooper et al., 2005).

A partir dessa base inicial, e após uma revisão geral, com inúmeros ajustes e correções de distorções, em alguns casos através de consulta a trabalhos originais, foi realizada a atualização da classificação dos perfis de solo, de acordo com a nova versão do Sistema Brasileiro de Classificação de Solos (Embrapa, 2006), seguida da exportação dos dados para um sistema gerenciador de banco de dados, o Microsoft Access $^{\circledR}$.

Na atualização da classificação dos perfis de solo, foram consideradas as características dos dois horizontes (superficial e subsuperficial) constantes do banco de dados, entre os critérios estabelecidos para distinção de atributos e de horizontes diagnósticos, e o conceito das classes de solo reconhecidas (Embrapa, 2006). O enquadramento taxonômico foi realizado até o quarto nível categórico e, quando pertinente, foi contemplada a distinção em quinto nível referente à ocorrência de caráter álico.

Graus de confiabilidade, representados por algarismos de 1 a 4 , foram adotados para expressar a exatidão do ajuste obtido no enquadramento taxonômico, referente a cada um dos quatro níveis categóricos, visto que muitos perfis necessitariam de dados complementares para atualização mais precisa da classificação. O valor 1 indica elevado grau de confiança, que se reduz progressivamente em direção a valores mais altos. $\mathrm{O}$ valor 2 expressa alguma dúvida com relação ao enquadramento taxonômico no nível categórico considerado, em função da ausência de algum dado analítico de menor relevância, porém a classificação anterior sugere o enquadramento atual como o mais provável. Já para o grau 3, seguiu-se uma linha similar de decisão, mas, nesse caso, a incerteza é maior, devido à falta de alguma informação essencial para o enquadramento taxonômico, sendo a classificação atual baseada exclusivamente na denominação anterior. $\mathrm{O}$ valor 4 foi utilizado para situações em que não foi possível a atualização. Esses padrões balizaram a avaliação da confiabilidade da classificação atual dos perfis do banco de dados em cada um dos quatro níveis categóricos.

Foi assim constituído um banco de dados de solos de abrangência nacional (Figura 1), que possui características quantitativas descritivas de formato alfa-numérico, do qual constam 10.950 horizontes, referentes a 5.479 perfis de solo e 57 colunas com variáveis independentes. Os perfis são identificados por códigos referentes à publicação-fonte em conjunto com sua numeração original, enquanto, para os horizontes, foram mantidas as mesmas designações adotadas nos trabalhos de origem. Além da classificação atualizada nos diferentes níveis categóricos e respectivo grau de confiabilidade, as demais variáveis constantes do banco de dados referem-se ao ano do levantamento, à classificação original, à declividade, à drenagem, ao símbolo e à profundidade do horizonte, posição relativa no perfil, à cor úmida, à composição macroclástica (calhaus e cascalhos), à granulometria (areia grossa, areia fina, silte e argila), ao teor de óxidos obtido pelo ataque sulfúrico $\left(\mathrm{SiO}_{2}, \mathrm{Al}_{2} \mathrm{O}_{3}, \mathrm{Fe}_{2} \mathrm{O}_{3}\right)$, ao $\mathrm{pH}$ em $\mathrm{H}_{2} \mathrm{O}$ e em $\mathrm{KCl}$, aos teores de $\mathrm{C}$ e matéria orgânica, ao $\mathrm{N}$ total, a elementos do complexo sortivo $\left(\mathrm{Ca}^{2+}, \mathrm{Mg}^{2+}, \mathrm{Ca}^{2+}+\right.$ $\mathrm{Mg}^{2+}, \mathrm{K}^{+}, \mathrm{Na}^{+}, \mathrm{Al}^{3+}, \mathrm{H}^{+}, \mathrm{H}+\mathrm{Al}$ ), à capacidade de troca catiônica (CTC), e à soma de bases, saturação por bases e saturação por alumínio. Cada perfil tem ainda uma indicação espacial relacionada à sua localização sobre a superfície terrestre, ou seja, suas coordenadas geográficas (latitude e longitude). $\mathrm{O}$ acesso ao banco de dados, com a classificação dos perfis atualizada, pode ser feito no endereço eletrônico: www.esalq.usp.br/ gerd. 


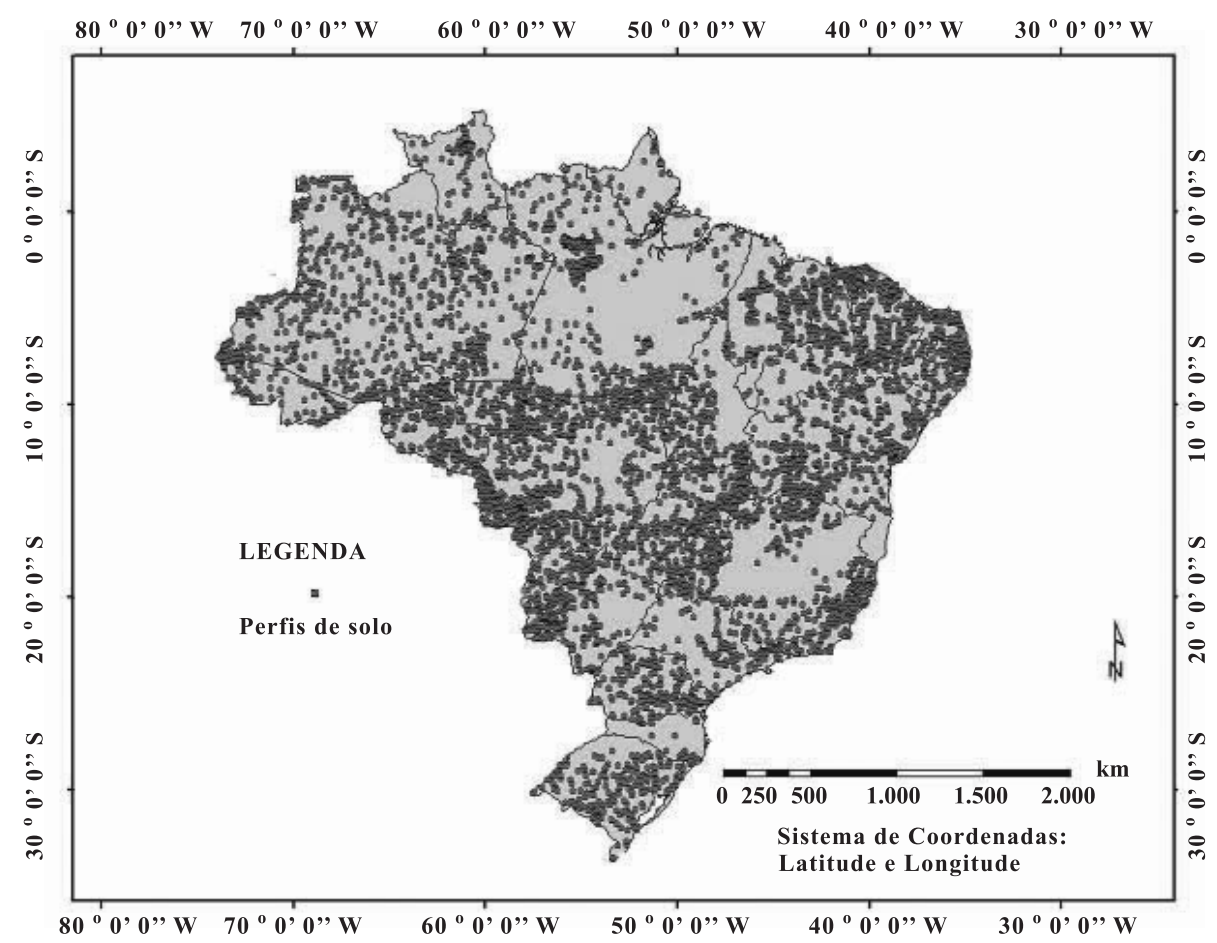

Figura 1. Mapa do Brasil com a divisão estadual e a distribuição espacial dos perfis de solo que integram o banco de dados.

Por falta de uma nomenclatura unificada dos perfis, a base de dados original (Cooper et al., 2005) só permitia aplicações quantitativas. A partir da atualização da classificação dos perfis, tornou-se possível a comparação com variáveis externas. Com o intuito de exemplificar algumas possibilidades de utilização da base atualizada, foram realizadas comparações entre classes de solo, em nível de ordem, e os tipos climáticos (Sparovek et al., 2007), altitude e situação geográfica dos perfis, obtidas, respectivamente, a partir do modelo de elevação global (EDC, 1996) e recorte geográfico a partir da malha de regiões e Unidades da Federação (IBGE, 2001). Todos esses dados foram incorporados ao banco de dados com o auxílio do programa $\operatorname{ArcGis}^{\circledR}$, a partir de arquivo shapefile com informações georreferenciadas de todo o território nacional (ESRI, 1999).

As variáveis consideradas referem-se a valores de altitude, em $\mathrm{m}$, assim como o tipo climático e o nome dos estados e da região geográfica onde situa-se cada perfil. Com relação à altitude, os valores de mediana, quartil inferior e quartil superior disponibilizaram informações mais acuradas sobre os dados em questão. Os quartis inferior e superior representam, respectivamente, os valores abaixo dos quais estão inseridos um quarto e três quartos dos dados. A mediana corresponde ao valor de altitude que divide a população dos perfis em dois conjuntos de igual tamanho. Já no que se refere ao clima, foi utilizada a classificação climática de Köppen, com relação aos dois primeiros critérios (zona e tipos climáticos) desta classificação. Foram consideradas as zonas climáticas $\mathrm{A}, \mathrm{B}$ e $\mathrm{C}$, que distinguem, respectivamente, clima tropical úmido, caracterizado por temperatura média do mês mais frio acima de $18^{\circ} \mathrm{C}$; clima seco, no qual a evaporação excede a precipitação; e clima úmido moderadamente quente, com temperatura do mês mais frio entre $3{ }^{\circ} \mathrm{Ce} 18^{\circ} \mathrm{C}$. Os tipos climáticos podem ser observados no quadro 3, representando as variações climáticas das zonas em questão, com as letras minúsculas (aplicadas aos grupos A e C) indicando particularidades do regime de chuvas: $\mathrm{f}$ clima sempre úmido, mês menos chuvoso com mais de 60 mm de precipitação; m - monçônico, úmido com pequeno período seco; s - com estação seca no verão; s' - com máximo de chuvas no inverno e outono; w - com marcada estação seca no inverno e verão chuvoso; w' - com máximo de chuvas no outono. Para a zona de clima seco (grupo B), as letras maiúsculas $\mathrm{S}$ e W indicam, respectivamente, climas semi-árido e árido, ou desértico.

\section{RESULTADOS E DISCUSSÃO}

\section{Atualização da classificação dos perfis de solo}

Embora não sejam disponíveis dados analíticos e morfológicos completos, e estejam faltando também informações de toda a extensão dos perfis de solo que 
compõem o banco de dados, a atualização da classificação foi em geral bastante satisfatória nos três primeiros níveis hierárquicos. Assim, no nível de ordem (primeiro nível), o enquadramento taxonômico foi realizado com máximo grau de confiabilidade (valor 1) para $96 \%$ dos perfis analisados, enquanto em nível de subordem e grande grupo, essa proporção reduziuse para $66 \%$ e $39 \%$, respectivamente. Para esses níveis, grau de confiabilidade secundário (valor 2) foi atribuído a $17 \%$ e $60 \%$ dos casos, respectivamente, enquanto a carência de informações complementares relativas a atributos importantes, dos quais o de maior significância refere-se a cor do horizonte subsuperficial, resultou em aumento da incerteza (expresso pelo valor 3) quanto à classificação de $17 \%$ dos perfis em nível de subordem. Apenas para 50 perfis analisados $(<1 \%$ do total $)$ não foi possível a classificação completa até o terceiro nível categórico (Grande Grupo), aos quais foi atribuído valor 4.

Já em quarto nível (Subgrupo), a maior quantidade de critérios distintivos levou a uma diminuição da certeza da atualização, expressa na pequena proporção dos perfis com máximo grau de confiabilidade (<1\%). A confiabilidade no enquadramento taxonômico foi considerada moderada (valor 2 ) para $70 \%$ dos perfis e baixa (valor 3) para $29 \%$ deles.

A partir dessa análise, fica evidenciada a maior confiabilidade no enquadramento taxonômico dos perfis nos níveis categóricos superiores, e um progressivo aumento da incerteza em direção aos níveis mais baixos. Por consequência, o máximo desvio é verificado no subgrupo (quarto nível categórico), que necessita ser reavaliado com base nos dados completos disponíveis nos respectivos relatórios dos levantamentos originais, para permitir sua utilização em estudos mais aprofundados e específicos que utilizem a base de dados.

Pela comparação entre a classificação anterior e o enquadramento atual dos perfis nos seus diversos níveis hierárquicos, vários aspectos relevantes foram observados, sobretudo no que respeita aos ajustes e à correspondência de critérios classificatórios adotados. Dessa avaliação, destacam-se algumas características expressas na denominação anterior que não encontram correspondência nas classes previstas pelo atual Sistema Brasileiro de Classificação de Solos (Embrapa, 2006), sobretudo no quarto nível categórico, com indivíduos de características especiais tendo que ser enquadrados como típicos, por não estarem conceituadas classes que possam diferenciá-los, o que resulta em perda de informação. Tal situação indica também o potencial do banco de dados como fonte de informações para o próprio desenvolvimento do sistema de classificação de solos adotado no país. Observações mais detalhadas sobre questões taxonômicas envolvidas na atualização da classificação dos perfis do banco de dados são apresentadas por Benedetti (2006).

\section{Abrangência e distribuição geográfica}

Com o objetivo de avaliar a abrangência e representatividade do banco de dados, bem como a distribuição geográfica das classes de solo em nível de ordem, os perfis foram agrupados por classes de primeiro nível categórico e, através de suas coordenadas, relacionados com as regiões e unidades da Federação onde ocorrem.

A figura 1 permite a visualização da distribuição dos perfis de solo no território nacional e nos diversos Estados da Federação, além de possibilitar uma avaliação prévia da representatividade e abrangência do banco de dados. Para uma avaliação mais acurada, é representada na figura 2 , pela união de escalas, a quantidade total de perfis, além de sua densidade dentro de cada unidade da Federação.

As regiões Centro-Oeste, Nordeste e Norte compreendem mais de $80 \%$ dos perfis (Quadro 1), o que indica uma boa distribuição geográfica, pois essas três regiões totalizam $82 \%$ do território brasileiro. Dessa forma, o restante dos perfis do banco de dados (16,9 \%) encontra-se distribuído pelas regiões Sudeste e Sul, cuja área representa $18 \%$ do território nacional.

Os estados de maior expressão geográfica, como Amazonas, Mato Grosso e Pará, são os que apresentam maior quantidade de perfis no banco de dados, e também abrangem quase todas as classes de solo, mas a densidade por $\mathrm{km}^{2}$ é baixa (Figura 2). O Estado de Mato Grosso, por exemplo, apresenta mais de 700 perfis, mas densidade espacial que não ultrapassa 90 perfis por $100.000 \mathrm{~km}^{2}\left(0,9\right.$ perfil por $\left.1.000 \mathrm{~km}^{2}\right)$. Ainda menos contemplado é o estado do Amazonas, que conta com mais de 650 perfis, mas com densidade inferior a 70 perfis por $100.000 \mathrm{~km}^{2}(0,7$ perfil por $1.000 \mathrm{~km}^{2}$ ). Em contrapartida, alguns Estados com número de perfis bem menor apresentam maior

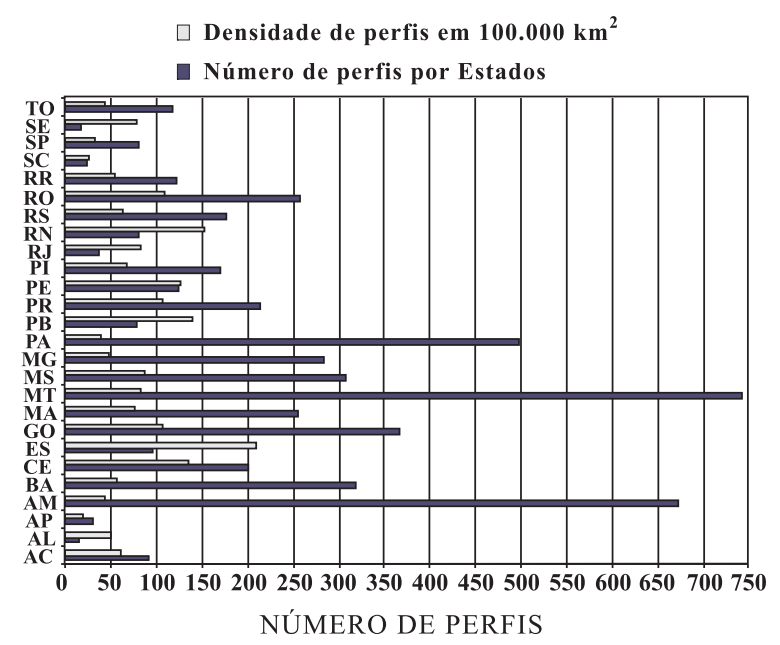

Figura 2. Representação gráfica do número e densidade de perfis de solo por Estado da Federação. 
Quadro 1. Distribuição percentual dos perfis do banco de dados, agrupados por classes de solo de primeiro nível categórico (ordem), em relação às diferentes regiões e Estados brasileiros

\begin{tabular}{|c|c|c|c|c|c|c|c|c|c|c|c|c|c|c|}
\hline \multirow{2}{*}{ Região } & \multicolumn{14}{|c|}{ Classe de solo } \\
\hline & $\mathbf{P}$ & $\mathbf{C}$ & M & $\mathbf{E}$ & $\mathbf{G}$ & $\mathbf{L}$ & $\mathbf{T}$ & $\mathbf{R}$ & $\mathbf{N}$ & O & $\mathbf{S}$ & $\mathbf{F}$ & V & Total \\
\hline & \multicolumn{14}{|c|}{$\%$} \\
\hline Centro-Oeste & 21,2 & 28,0 & 20,9 & 16,3 & 21,7 & 33,8 & 6,9 & 30,8 & 19,6 & 0,0 & 30,5 & 24,5 & 26,1 & 26,4 \\
\hline Nordeste & 21,3 & 18,8 & 36,4 & 12,8 & 12,0 & 18,3 & 63,6 & 30,2 & 11,6 & 36,4 & 46,9 & 26,5 & 62,2 & 23,5 \\
\hline Norte & 46,1 & 24,1 & 10,7 & 59,3 & 53,1 & 25,8 & 17,7 & 27,4 & 35,8 & 0,0 & 10,0 & 45,9 & 1,8 & 33,3 \\
\hline Sudeste & 5,5 & 15,3 & 6,4 & 11,6 & 8,2 & 15,4 & 1,7 & 8,4 & 8,8 & 45,5 & 2,2 & 0,4 & 3,6 & 9,2 \\
\hline Sul & 5,9 & 13,8 & 25,7 & 0,0 & 5,0 & 6,7 & 10,0 & 3,1 & 24,2 & 18,2 & 10,4 & 2,6 & 6,3 & 7,7 \\
\hline \multicolumn{15}{|l|}{ Estado } \\
\hline Acre & 3,2 & 2,8 & 1,1 & 0,0 & 1,2 & 0,3 & 10,8 & 0,5 & 1,1 & 0,0 & 0,0 & 0,0 & 1,8 & 1,7 \\
\hline Alagoas & 0,3 & 0,0 & 0,0 & 3,5 & 0,5 & 0,2 & 0,0 & 0,4 & 0,0 & 0,0 & 0,0 & 0,0 & 0,0 & 0,3 \\
\hline Amapá & 0,2 & 0,0 & 0,0 & 0,0 & 5,0 & 0,6 & 0,0 & 0,0 & 0,7 & 0,0 & 0,0 & 1,8 & 0,0 & 0,5 \\
\hline Amazonas & 18,7 & 7,0 & 0,0 & 52,3 & 25,4 & 8,5 & 6,1 & 8,4 & 11,7 & 0,0 & 4,0 & 17,4 & 0,0 & 12,5 \\
\hline Bahia & 3,8 & 11,9 & 10,2 & 7,0 & 2,5 & 4,5 & 7,4 & 8,8 & 3,5 & 18,2 & 14,8 & 0,4 & 25,2 & 5,9 \\
\hline Ceará & 4,3 & 0,8 & 4,3 & 0,0 & 0,2 & 2,2 & 15,6 & 4,6 & 2,2 & 0,0 & 13,3 & 1,8 & 3,6 & 3,7 \\
\hline Espírito Santo & 1,1 & 3,0 & 2,1 & 2,3 & 1,0 & 2,8 & 0,0 & 2,2 & 1,5 & 27,3 & 0,0 & 0,0 & 0,0 & 1,8 \\
\hline Goiás & 3,6 & 14,4 & 4,3 & 2,3 & 1,5 & 12,7 & 1,7 & 4,6 & 7,3 & 0,0 & 0,4 & 4,0 & 0,0 & 6,8 \\
\hline Maranhão & 5,5 & 1,5 & 2,1 & 0,0 & 6,2 & 4,7 & 4,3 & 3,7 & 1,8 & 0,0 & 1,8 & 16,3 & 1,8 & 4,7 \\
\hline Mato Grosso & 13,9 & 12,0 & 5,3 & 7,0 & 15,0 & 14,9 & 1,7 & 20,0 & 7,7 & 0,0 & 8,8 & 14,8 & 7,2 & 13,8 \\
\hline Mato Grosso do Sul & 3,5 & 1,8 & 11,2 & 7,0 & 5,7 & 6,3 & 3,5 & 6,3 & 4,8 & 0,0 & 21,2 & 5,3 & 18,9 & 5,7 \\
\hline Minas Gerais & 2,9 & 11,0 & 4,3 & 2,3 & 4,5 & 9,1 & 1,7 & 4,6 & 4,4 & 9,1 & 0,9 & 0,0 & 3,6 & 5,3 \\
\hline Pará & 12,4 & 6,3 & 1,1 & 0,0 & 9,5 & 8,7 & 0,9 & 9,5 & 9,4 & 0,0 & 0,4 & 14,8 & 0,0 & 9,3 \\
\hline Paraíba & 1,6 & 0,8 & 0,0 & 2,3 & 0,0 & 0,4 & 11,3 & 2,3 & 1,1 & 0,0 & 2,2 & 0,0 & 10,8 & 1,5 \\
\hline Paraná & 2,4 & 10,4 & 6,4 & 0,0 & 1,7 & 5,2 & 0,0 & 1,9 & 13,0 & 13,6 & 0,0 & 0,0 & 0,0 & 4,0 \\
\hline Pernambuco & 1,9 & 1,0 & 2,1 & 0,0 & 1,0 & 1,9 & 10,4 & 3,3 & 1,8 & 4,5 & 6,2 & 0,0 & 5,4 & 2,3 \\
\hline Piauí & 2,5 & 0,6 & 10,2 & 0,0 & 0,0 & 3,6 & 8,7 & 4,3 & 1,1 & 0,0 & 3,5 & 6,2 & 5,4 & 3,2 \\
\hline Rio de Janeiro & 0,7 & 1,0 & 1,1 & 2,3 & 2,7 & 0,6 & 0,0 & 0,4 & 0,0 & 0,0 & 1,3 & 0,0 & 0,0 & 0,7 \\
\hline Rio Grande do Norte & 1,3 & 1,9 & 4,3 & 0,0 & 1,0 & 0,6 & 6,1 & 2,2 & 0,0 & 13,6 & 3,3 & 0,9 & 8,1 & 1,5 \\
\hline Rio Grande do Sul & 3,1 & 1,4 & 19,3 & 0,0 & 3,2 & 1,1 & 10,0 & 1,1 & 10,1 & 0,0 & 10,4 & 2,6 & 6,3 & 3,3 \\
\hline Rondônia & 7,3 & 3,3 & 6,4 & 2,3 & 4,2 & 3,5 & 0,0 & 5,4 & 6,2 & 0,0 & 0,0 & 2,2 & 0,0 & 4,8 \\
\hline Roraima & 3,0 & 0,8 & 0,0 & 4,7 & 3,0 & 2,0 & 0,0 & 1,8 & 2,9 & 0,0 & 2,9 & 3,1 & 0,0 & 2,3 \\
\hline Santa Catarina & 0,4 & 2,0 & 0,0 & 0,0 & 0,0 & 0,4 & 0,0 & 0,1 & 1,1 & 4,5 & 0,0 & 0,0 & 0,0 & 0,4 \\
\hline São Paulo & 0,9 & 0,5 & 0,0 & 4,7 & 0,0 & 3,0 & 0,0 & 1,2 & 2,9 & 9,1 & 0,0 & 0,4 & 0,0 & 1,5 \\
\hline Sergipe & 0,2 & 0,0 & 2,1 & 0,0 & 0,5 & 0,1 & 0,0 & 0,4 & 0,0 & 0,0 & 1,8 & 0,9 & 1,8 & 0,3 \\
\hline Tocantins & 1,2 & 3,7 & 2,1 & 0,0 & 4,2 & 2,2 & 0,0 & 1,8 & 3,5 & 0,0 & 2,7 & 7,1 & 0,0 & 2,2 \\
\hline
\end{tabular}

P: Argissolos, C: Cambissolos, M: Chernossolos, E: Espodossolos, G: Gleissolos, L: Latossolos, T: Luvissolos, R: Neossolos, N: Nitossolos, O: Organossolos, S: Planossolos, F: Plintossolos, V: Vertissolos.

densidade por $\mathrm{km}^{2}$, como observado para o Espírito Santo, com mais de 200 perfis por $100.000 \mathrm{~km}^{2}$ (2 perfis por $1.000 \mathrm{~km}^{2}$ ) e Rio Grande do Norte, com mais de 150 perfis por $100.000 \mathrm{~km}^{2}\left(1,5\right.$ perfis por $\left.1.000 \mathrm{~km}^{2}\right)$. Já estados como Santa Catarina, Paraná e Mato Grosso apresentam boa distribuição dos seus perfis, enquanto em outros, como Minas Gerais e São Paulo, há uma certa concentração em determinadas regiões (Figura 1).

Quanto às classes em nível de ordem (primeiro nível categórico), Argissolos e Latossolos encontramse representados em todos os estados brasileiros. No estado do Amazonas estão $19 \%$ dos perfis de Argissolos e $9 \%$ dos Latossolos (Quadro 1), o que se explica com a presença expressiva de solos com baixíssima capacidade de troca catiônica e alta saturação por $\mathrm{Al}$ nos domínios pedobioclimáticos da Amazônia (Resende et al., 2007). Ainda neste Estado, encontram-se a maior parte dos Espodossolos, correspondendo a $52 \%$ do total, e grande parte dos Gleissolos (25\%). Os Plintossolos apresentam também grande proporção de perfis neste Estado, assim como no Maranhão, Mato Grosso e Pará. Os Vertissolos apresentaram maior expressão nos Estados da Bahia, Mato Grosso do Sul e Paraíba. Em alguns Estados do Nordeste, como Pernambuco, Paraíba e Ceará, há uma grande quantidade de perfis de solo que apresentam horizonte $\mathrm{B}$ textural com alta atividade de argila conjugada com alta saturação por bases, referentes à classe dos Luvissolos. Solos jovens como os Neossolos estão representados em quase todos os Estados brasileiros, sendo a maior concentração verificada no Mato Grosso, que abrange $20 \%$ dos seus perfis. No tocante aos Cambissolos, ocorre maior concentração de perfis no estado de Goiás, com mais de $14 \%$ do total.

Apesar do seu caráter generalizado, os resultados dessa avaliação podem servir como instrumento auxiliar para definição de pesquisas futuras a serem 
desenvolvidas a partir do banco de dados. Além disso, pelo fato de estar georreferenciado, o banco de dados permite novas aplicações para avaliação da distribuição dos perfis, que atendam a necessidades específicas de estudo.

\section{Classes de solo relacionadas a altitude e clima}

Considerando-se a altitude, expressa em metros acima do nível médio do mar, na qual situam-se os perfis de solo do banco de dados, nota-se que não há uma relação direta entre esta característica e as classes de solo de primeiro nível categórico, cujas cotas de ocorrência na paisagem brasileira são muito variáveis (Quadro 2), em concordância com os resultados obtidos por Sousa (2005), que verificou consideráveis variações de altitude para Argissolos, Latossolos, Nitossolos, Neossolos e Cambissolos. Os Latossolos, por exemplo, são encontrados desde 1 a $2863 \mathrm{~m}$ de altitude. Grande amplitude altimétrica entre áreas de ocorrência de solos dessa classe foi também observada por Lacerda et al. (2005) na região do Distrito Federal.

A distribuição dos dados é também bastante assimétrica. Por isso, foram agrupados por quartil para melhor representar as variações de altitude referentes a cada classe de solo em nível de ordem (Quadro 2).

Apesar de haver uma grande variação altimétrica para a maioria das classes de solo, nota-se, para algumas delas, a tendência à concentração de perfis em determinadas faixas de altitude. Nas partes mais altas da paisagem brasileira há uma predominância de Latossolos, entretanto, quando analisados os dados de quartis e mediana (Quadro 2), verificou-se que os
Cambissolos têm, dentre todas as classes, maior proporção dos seus perfis situados em áreas mais elevadas, seguidos dos Latossolos. Analisando-se outras ordens, pôde-se constatar que a maioria dos perfis de Espodossolo ocorre em altitudes mais baixas, em média a $161 \mathrm{~m}$, e com quartis inferior e superior a 83 e $110 \mathrm{~m}$, respectivamente. Portanto, $75 \%$ dos Espodossolos do banco de dados foram descritos em altitudes iguais ou menores que $110 \mathrm{~m}$, mas alguns perfis com cotas ao redor de $1.000 \mathrm{~m}$ contribuíram para elevação do valor da altitude média. Também os perfis de Plintossolos predominam em cotas mais baixas (201 m para o quartil superior), embora sejam encontrados em atitudes que excedem os 1.000 m. Já os Gleissolos apresentam média de $160 \mathrm{~m}$ e quartis a 32 e 199 m, e não constam do banco de dados perfis situados em altitudes superiores a $910 \mathrm{~m}$.

Os solos que apresentam menor valor de altitude máxima são os Vertissolos, encontrados entre 29 e $718 \mathrm{~m}$. Porém, os valores dos quartis mostram que metade dos perfis desta classe de solo se encontra na faixa de 122 a $394 \mathrm{~m}$. Planossolos e Luvissolos também apresentam valores bem próximos da faixa de distribuição dos Vertissolos, e as altitudes máximas de ocorrência de seus perfis não ultrapassam os $900 \mathrm{~m}$. Os Nitossolos são encontrados em altitudes que variam de 1 a $1.420 \mathrm{~m}$, com média de $412 \mathrm{~m}$, concordando com a referência de Miklos (1992), que registrou a ocorrência de Nitossolos em altitudes de aproximadamente $550 \mathrm{~m}$ na região de Botucatu, estado de São Paulo. Apesar da ampla abrangência de altitudes de ocorrência de Argissolos (1 a $1.505 \mathrm{~m}$ ) e Neossolos (1 a $1.303 \mathrm{~m}$ ), a maioria de seus perfis situase em locais que não ultrapassam $300 \mathrm{~m}$ para os Argissolos e $500 \mathrm{~m}$ para os Neossolos (Quadro 2).

Quadro 2. Altitudes de locais onde ocorrem as classes de solo de primeiro nível categórico

\begin{tabular}{|c|c|c|c|c|c|c|}
\hline \multirow{2}{*}{ Classe de solo } & \multicolumn{6}{|c|}{ Altitude } \\
\hline & Mínima & Máxima & $\mathbf{Q} 1^{(1)}$ & $\mathrm{Q} 2^{(2)}$ & $\mathrm{Q} 3^{(3)}$ & Média \\
\hline Argissolos & 1 & 1.505 & 99 & 195 & 317 & 255 \\
\hline Cambissolos & 1 & 2.426 & 265 & 500 & 773 & 543 \\
\hline Chernossolos & 38 & 913 & 152 & 272 & 514 & 346 \\
\hline Espodossolos & 1 & 1.040 & 83 & 99 & 110 & 161 \\
\hline Gleissolos & 1 & 910 & 32 & 98 & 199 & 160 \\
\hline Latossolos & 1 & 2.863 & 189 & 361 & 612 & 425 \\
\hline Luvissolos & 1 & 896 & 150 & 256 & 389 & 287 \\
\hline Neossolos & 1 & 1.303 & 103 & 291 & 474 & 323 \\
\hline Nitossolos & 1 & 1.420 & 159 & 343 & 592 & 412 \\
\hline Organossolos & 1 & 929 & 14 & 71 & 493 & 226 \\
\hline Planossolos & 1 & 845 & 97 & 152 & 300 & 215 \\
\hline Plintossolos & 1 & 1.161 & 63 & 107 & 201 & 157 \\
\hline Vertissolos & 29 & 718 & 122 & 200 & 394 & 254 \\
\hline
\end{tabular}

${ }^{(1)}$ Quartil inferior. ${ }^{(2)}$ Mediana. ${ }^{(3)}$ Quartil superior. 
A relação entre classes de solo de primeiro nível categórico e clima foi avaliada por zona e tipo climáticos da classificação de Köppen (Quadro 3).

$\mathrm{Na}$ zona de clima tropical úmido (zona $\mathrm{A}$ ), caracterizada por temperatura média do mês mais frio acima de $18{ }^{\circ} \mathrm{C}$, estão localizados $81 \%$ dos perfis do banco de dados. Nesta zona, os tipos climáticos com inverno seco (clima de savana, Aw) e com uma pequena estação seca (clima de monções, Am) abrangem $35 \%$ e $23 \%$ dos perfis, respectivamente. Este resultado, em confronto com o estudo de Sparovek et al. (2007), que registra o domínio de clima tropical úmido (zona A) em $84 \%$ do território brasileiro, é também indicativo da representatividade dos perfis do banco de dados. A abrangência dos tipos climáticos Aw e Am, estimada no trabalho mencionado, coadunase também com a proporção dos perfis do banco de dados relacionados a eles. Além disso, as zonas de clima seco (zona B) representaram, naquele estudo, $5 \%$ do território nacional, enquanto os perfis sob essa condição ambiental equivalem a $6 \%$ do total. A zona $\mathrm{C}$, que representa climas úmidos e moderadamente quentes, com temperatura do mês mais frio na faixa de $3{ }^{\circ} \mathrm{C}$ a $18{ }^{\circ} \mathrm{C}$, abrange $12 \%$ dos perfis, de novo em concordância com a avaliação de Sparovek et al. (2007), que distingue $11 \%$ do território nacional sob domínio dessa zona climática.

Quanto às classes de solo em nível de ordem, todas elas estão representadas em áreas dos tipos climáticos Aw, Am e Af. Várias classes apresentam a maior ocorrência de perfis sob clima tropical úmido de savanas com inverno seco e chuvas máximas de verão (Aw), como Latossolos, Cambissolos e Neossolos, com máxima expressão em áreas sob estas condições ambientais. Argissolos, Espodossolos, Gleissolos e Plintossolos, por outro lado, têm a grande maioria de seus perfis distribuídos entre os tipos climáticos Aw e Am.

Por sua vez, grande parte dos perfis de Chernossolos, Nitossolos e Organossolos encontra-se sob os tipos climáticos Aw e $\mathrm{Cf}$ (clima mesotérmico úmido em todas as estações do ano).

Os Espodossolos apresentam $92 \%$ de seus perfis na zona tropical úmida (A), sendo $43 \%$ em domínio do clima Af, que se caracteriza por uma boa distribuição de chuvas durante o ano e ausência de estação seca. Como registrado anteriormente, $52 \%$ dos perfis de Espodossolos situam-se no estado do Amazonas (Quadro 1), região de maior expressão do clima Af, que ocorre preferencialmente na Amazônia ocidental (Botton et al., 2002).

Apesar de $35 \%$ dos Vertissolos se encontrarem sob clima Aw, considerável proporção ocorre também em áreas de climas secos (zona B). O tipo climático BS (clima semi-árido) compreende $29 \%$ dos perfis desta classe. Outra classe que também apresenta expressiva concentração neste tipo climático é a dos Luvissolos, com $25 \%$ de seus perfis.

Os Neossolos, como era de se esperar, apresentam representantes de seus perfis em todos os tipos climáticos, pois, devido ao baixo grau de desenvolvimento

Quadro 3. Distribuição das classes de solo de primeiro nível categórico, referente à percentagem de perfis, em função da zona e tipos climáticos da classificação de Köppen

\begin{tabular}{|c|c|c|c|c|c|c|c|c|c|c|c|c|c|c|}
\hline \multirow{2}{*}{$\begin{array}{c}\text { Classificação } \\
\text { climática de } \\
\text { Köppen }\end{array}$} & \multicolumn{14}{|c|}{ Classe de solo ${ }^{(1)}$} \\
\hline & $\mathbf{P}$ & C & M & $\mathbf{E}$ & G & $\mathbf{L}$ & $\mathbf{T}$ & $\mathbf{R}$ & $\mathbf{N}$ & $\mathbf{O}$ & $\mathbf{S}$ & $\mathbf{F}$ & V & Total \\
\hline \multicolumn{15}{|l|}{ Zonas } \\
\hline $\mathrm{A}$ & 85,6 & 71,0 & 64,7 & 97,7 & 93,5 & 82,3 & 63,2 & 82,0 & 69,4 & 72,7 & 69,0 & 96,5 & 64,9 & 81,4 \\
\hline B & 4,5 & 8,2 & 8,6 & 0,0 & 0,0 & 3,8 & 26,0 & 10,5 & 1,5 & 0,0 & 20,1 & 0,9 & 28,8 & 6,3 \\
\hline $\mathrm{C}$ & 9,9 & 20,8 & 26,7 & 2,3 & 6,5 & 14,0 & 10,8 & 7,5 & 29,2 & 27,3 & 10,8 & 2,6 & 6,3 & 12,3 \\
\hline \multicolumn{15}{|l|}{ Tipos } \\
\hline Af & 12,8 & 3,4 & 1,1 & 43,0 & 18,0 & 6,8 & 1,7 & 7,1 & 6,2 & 9,1 & 5,5 & 11,5 & 7,2 & 9,0 \\
\hline $\mathrm{Am}$ & 32,3 & 16,2 & 1,1 & 25,6 & 32,9 & 19,0 & 16,0 & 20,3 & 24,8 & 13,6 & 4,6 & 28,3 & 3,6 & 23,1 \\
\hline As & 1,2 & 0,0 & 2,1 & 0,0 & 0,0 & 0,5 & 5,2 & 0,9 & 1,1 & 0,0 & 1,8 & 0,0 & 3,6 & 0,9 \\
\hline$A s^{\prime}$ & 1,5 & 1,4 & 4,8 & 2,3 & 2,0 & 0,7 & 5,2 & 2,0 & 0,0 & 13,6 & 9,1 & 1,3 & 8,1 & 1,8 \\
\hline Aw & 25,8 & 44,7 & 39,6 & 23,3 & 30,7 & 43,1 & 11,3 & 38,7 & 31,7 & 36,4 & 36,3 & 33,8 & 35,1 & 34,7 \\
\hline$A w^{\prime}$ & 12,0 & 5,2 & 16,0 & 3,5 & 10,0 & 12,3 & 23,8 & 13,0 & 5,5 & 0,0 & 11,7 & 21,6 & 7,2 & 11,9 \\
\hline BS & 4,3 & 7,7 & 8,6 & 0,0 & 0,0 & 3,7 & 25,1 & 10,0 & 1,5 & 0,0 & 17,5 & 0,9 & 28,8 & 6,0 \\
\hline $\mathrm{BW}$ & 0,2 & 0,5 & 0,0 & 0,0 & 0,0 & 0,1 & 0,9 & 0,5 & 0,0 & 0,0 & 2,7 & 0,0 & 0,0 & 0,3 \\
\hline $\mathrm{Cf}$ & 8,5 & 15,2 & 25,7 & 0,0 & 6,0 & 10,0 & 10,0 & 5,9 & 26,1 & 27,3 & 10,8 & 2,6 & 6,3 & 10,0 \\
\hline $\mathrm{Cs}$ & 0,0 & 0,0 & 0,0 & 0,0 & 0,0 & 0,1 & 0,0 & 0,4 & 0,4 & 0,0 & 0,0 & 0,0 & 0,0 & 0,1 \\
\hline $\mathrm{Cw}$ & 1,5 & 5,6 & 1,1 & 2,3 & 0,5 & 3,8 & 0,9 & 1,2 & 2,8 & 0,0 & 0,0 & 0,0 & 0,0 & 2,2 \\
\hline
\end{tabular}

(1) P: Argissolos, C: Cambissolos, m: Chernossolos, E: Espodossolos, G: Gleissolos, L: Latossolos, T: Luvissolos, R: Neossolos, N: Nitossolos, O: Organossolos, S: Planossolos, F: Plintossolos, V: Vertissolos. 
pedogenético, é natural que ocorram em variados ambientes. De forma paradoxal, chama-se atenção para solos em estágio de intemperismo-lixiviação muito avançado, como os Latossolos, que também encontram-se distribuídos por todos os tipos climáticos.

A classe dos Planossolos mostrou boa distribuição de perfis nas três zonas climáticas, sendo Aw, BS e Cf os tipos climáticos de maior expressão, abrangendo $36 \%, 12 \%$ e $11 \%$ dos perfis, respectivamente.

Latossolos, Neossolos e Nitossolos foram as únicas classes identificadas sob clima Cs (mesotérmico com verão quente), com pequena proporção de perfis para cada uma delas $(0,5 \%)$, e que representam somente $0,1 \%$ do total, dada a exígua expressão geográfica deste tipo climático, que ocorre apenas em pequena região do nordeste brasileiro (Botton et al., 2002).

\section{CONCLUSÕES}

1. Na atualização da classificação dos perfis de solo do banco de dados, foi obtido um grau de confiabilidade bastante satisfatório, mas com um aumento progressivo da incerteza em direção aos níveis hierárquicos mais baixos, de modo que, principalmente para o quarto nível categórico (subgrupo), há necessidade de reavaliação do enquadramento taxonômico a partir dos dados completos dos perfis para sua utilização em estudos mais aprofundados e específicos que utilizem essa base de dados.

2. A avaliação da distribuição dos perfis de solo indicou uma boa representatividade do conjunto de dados no âmbito do território nacional, e pode servir como instrumento auxiliar na orientação de pesquisas futuras a partir dessa base de informações.

3. Com a estruturação atual do banco de dados tornou-se possível avaliar qualitativamente variáveis externas, como clima e altitude, mas não foram observadas, neste trabalho, relações específicas entre essas variáveis e as classes de solo em nível de ordem, embora para algumas delas tenham sido identificadas faixas de altitude e ambientes preferenciais de ocorrência.

\section{LITERATURA CITADA}

ASSAD, E.D. \& SANO, E.E. Sistema de informações geográficas: Aplicações na Agricultura. Brasília, Embrapa, 1998. $434 \mathrm{p}$.

BENEDETTI, M.M. Estruturação e atualização da classificação pedológica de uma base de dados de perfis de solos do Brasil. Piracicaba, Escola Superior de Agricultura "Luiz de Queiroz", 2006. 110p. (Tese de Mestrado).
BOTTON, M.; HICKEL, E.; PEREIRA, A.R.; ANGELOCCI, L.R. \& SENTELHAS, P.C. Agrometeorologia: Fundamentos e aplicações práticas. Guaíba, Agropecuária, 2002. 478p.

COOPER, M.; MENDES, L.M.S.; SILVA, W.L.C. \& SPAROVEK, G. A national soil profile database for Brazil available to international scientists. Soil Sci. Soc. Am. J., 69:649-652, 2005.

COOTE, D.R. \& McDONALD, K.B. The canadian soil database. In: SUMNER, M.E., ed. Handbook of soil science. Boca Raton, CRC Press, 1999. p.H41-H51.

EDC (1996) GTOPO30 - Global 30 Arc-Second Elevation Data Set. U.S. Geological Survey's EROS Data Center. Disponível em: <http://www.edcdaac.usgs.gov/gtopo30/ gtopo30.html>. Acesso em 22 maio 2006.

ENVIROMENTAL SYSTENS RESEARCH INSTITUTE ESRI. Software. Washington, 1999.

EMPRESA BRASILEIRA DE PESQUISA AGROPECUÁRIA EMBRAPA. Centro Nacional de Pesquisa de Solos. Sistema brasileiro de classificação de solos. 2.ed. Rio de Janeiro, 2006. 306p.

FAO. The digitized soil map of the world including derived soil properties. Rome, 1996. CD-ROM.

INSTITUTO BRASILEIRO DE GEOGRAFIA E ESTATÍSTICA - IBGE. Malha municipal digital do Brasil: Situação em 2001. Rio de Janeiro, 2001. CD-ROM

LACERDA, M.P.C.; BARBOSA, I.O.; MENESES, P.R.; ROSA, J.W.C. \& ROIG, H.L. Aplicação de geotecnologias em correlações entre solos, geomorfologia, geologia e vegetação nativa no Distrito Federal, DF. In: SIMPÓSIO BRASILEIRO DE SENSORIAMENTO REMOTO, 12. Goiânia, 2005. Anais. Goiânia, INPE, 2005. p.2211-2218. CD-ROM.

MIKLOS, A.A. Biodynamique d'une couverture pédologique dans la region de Botucatu (Brésil-SP). Paris, Universitè Pierre \& Marie Curie, Universitè Paris VI, 1992. 438p. (Tese de Doutorado)

NEMES, A.; SCHAAP, M.G.; LEIJ, F.J. \& WÖSTEN, J.H.M. Description of the unsaturated soil hydraulic database. UNSODA version 2.0. J. Hydrol., 251:151-162, 2001.

NEMES, A.; WOSTEN, J.H.M.; LILLY, A. \& OUDE VOS HARR, J.H. Evolution of different procedures to interpolate particle - size distributions to achieve compatibility within soil databases. Geoderma, 90:87-202, 1999.

RESENDE, M.; CURI, N.; REZENDE, S.B. \& CORRÊA, G.F. Pedologia: Base para distinção de ambientes. 5.ed. Lavras, Universidade Federal de Lavras, 2007. 322p.

SOIL SURVEY STAFF - SSS. National soil information system (NASIS): Soil interpretation and information dissemination sub-system. Draft requirements statement. Lincoln, USDA, Natural Resources Conservation Service, National Soil Survey Center, 1991. 67p.

SOUSA, J.A.G.J. Sensoriamento remoto e sistemas de informações geográficas na caracterização de solos e quantificação de seus atributos. Piracicaba, Escola Superior de Agricultura "Luiz de Queiroz", 2005. 141p. (Tese de Mestrado) 
SPAROVEK, G.; De Jong van LIER Q. \& DOURADO NETO,

D. Computer assisted Köppen climate classification for Brazil. Inter. J. Climatol., 27:257-266, 2007. DOI: 10.1002/ JOC. 1384. van ENGELEN, V.W.P. SOTER: The world soils and terrain database. In: SUMNER, M.E., ed. Handbook of soil science. Boca Raton, CRC Press, 1999. p.H19-H28. 